\title{
Rios urbanos e a política de canalização
}

\author{
Urban rivers and channelization policies
}

\section{Beatriz Fagundes ${ }^{1}$}

Palavras-chave:

Presidente Prudente

Córregos urbanos

Canalizações

\begin{abstract}
Resumo
A maioria dos cursos d'água da cidade de Presidente Prudente se encontra com canalização e muitos outros são inacessíveis à população. Os cursos d'água da cidade estão degradados com leitos assoreados, processos erosivos intensos, acúmulo de lixo nas margens e nas áreas adjacentes ao córrego. Por isso, este estudo teve como objetivo investigar como as intervenções e ações do poder público afetaram os córregos urbanos de Presidente Prudente ao longo do tempo, bem como, as leis de proteção a essas águas e a sua aplicabilidade durante o processo de expansão urbana. O estudo compreendeu trabalhos de campo, entrevistas com citadinos, análise de imagens de satélite do Google Earth, de pesquisas que sobre questões ambientais e de produção do espaço urbano de Presidente Prudente, assim como, a análise de vários documentos. Os resultados revelaram que o planejamento urbano de Presidente Prudente privilegiou o setor imobiliário, sem considerar o marco legal que protege os cursos d'água da cidade. Na estruturação da cidade, suas águas foram levadas a circular por galerias de concreto, com subsequente construção de espaços públicos de lazer como solução imediata para os problemas ambientais instalados nos fundos de vale. Esse processo, associado à falta de espaços urbanos valorizando a presença das águas na paisagem, contribuiu para que a população aceitasse as canalizações como destino final das águas urbanas.
\end{abstract}

\section{Keywords:}

Presidente Prudente

Urban streams

Channelization

\begin{abstract}
Most of the watercourses in the city of Presidente Prudente, state of São Paulo, Brazil, are channeled and many others are inaccessible to the population. The city's watercourses are degraded with silted beds, intense erosive processes, garbage accumulation on their banks and alongside the streams. Therefore, this study aimed to investigate how the interventions and actions of public authorities have affected the urban streams of Presidente Prudente over time, as well as the relevant protection laws and their enforcement during the urban expansion process. The study comprised fieldwork, interviews with city dwellers, Google Earth satellite image analysis, research on environmental issues and on urban space production, as well as the examination of various documents. The results showed that the city's urban planning favored the real estate sector, without consideration of the legal framework protecting the city's watercourses. In structuring the city, its waters were led to flow through concrete channels, with subsequent construction of public leisure spaces as an immediate solution to the environmental problems caused in the valley floors. This process, coupled with a lack of
\end{abstract}

1 Universidade Estadual Paulista "Júlio de Mesquita Filho", Presidente Prudente, São Paulo, Brasil. E-mail: beafagundes@yahoo.com.br 
urban spaces valuing the presence of waters in the landscape, contributed to th e population accepting channelization as the final fate of urban waters.

\section{INTRODUÇÃO}

A fundação da cidade de Presidente Prudente SP se deu a partir da substituição, ao longo do tempo, dos "objetos naturais" por "objetos fabricados, objetos técnicos" (SANTOS, 2002), que garantiram a chegada e a permanência de pioneiros e a integração deste espaço à economia cafeeira. Nesse processo, o espaço urbano foi produzido, com formas "herdadas, reconstruídas sob uma nova organização com formas novas em construção" (SUERTEGARAY, 2000, p. 18). Esse "sistema material" baseado no domínio da técnica que, em "momentos históricos diferentes" (SANTOS, 2002), foi se sobrepondo às águas e que resultou na atual paisagem urbana.

A paisagem urbana de Presidente Prudente possui poucos ambientes com a presença da água como fontes, córregos e lagos. Vale ressaltar que a cidade se estabeleceu sobre um denso sistema hidrográfico constituído por pequenos cursos d'água, ou seja, vários córregos das bacias hidrográficas dos rios Santo Anastácio e Do Peixe - os principais rios do município. A maioria dos cursos de água da cidade é canalizada e aqueles que não são, se apresentam inacessíveis à população. Muitos degradados, apresentando assoreamento no seu leito, com processos erosivos intensos e acúmulo de lixo em suas margens e nas áreas adjacentes ao córrego.

O presente estudo teve como objetivo investigar como as intervenções e ações do poder público afetaram os córregos urbanos de Presidente Prudente ao longo do tempo e, se as leis de proteção relevantes e sua aplicação foram contempladas durante o processo de expansão urbana. Assim, o estudo procurou entender como as políticas urbanas locais consideravam e têm considerado os córregos no tecido urbano e verificou o estado de conservação dessas áreas de fundo de vale.

\section{METODOLOGIA}

Para atingir o objetivo proposto, foram analisados os requerimentos de outorga de canalização, que se encontram arquivados no Departamento de Águas e Energia Elétrica (DAEE), unidade de Presidente Prudente. Esses documentos permitiram uma visão geral dos cursos d'água da cidade a partir de 2002, quando as solicitações de aprovação de canalização foram elaboradas pela Prefeitura Municipal e enviadas ao DAEE. Antes desta data, nenhum registro de canalização de cursos d'água foi encontrado, apenas projetos cartográficos do arquivo histórico do município.

Assim, para entender como ocorreram as intervenções, anteriores a 2002, foram examinadas várias pesquisas que abordam a questão ambiental e a produção do espaço urbano, que teve por consequência a degradação, retificação e canalização dos cursos d'água da área urbana de Presidente Prudente.

Foram consultados também: o Plano Diretor do Município de 1969 (PLANO..., 1969); o Parecer técnico referente à canalização de córregos na cidade de Presidente Prudente do Ministério Público do Estado de São Paulo - autos no 439/05 (SÃO PAULO, 2005a); a Política Estadual de Recursos Hídricos - Lei n ${ }^{\circ}$ 7.663/1991 (SÃO PAULO, 1991) e o Código Florestal (BRASIL, 1965) dentre outros documentos.

Imagens de satélites diretamente do Google Earth 2017-2018, foram utilizadas para localizar os cursos d'água e identificar a ocupação urbana nessas áreas de fundos de vale. Trabalhos de campo foram realizados para confirmar e coletar dados sobre o estado de conservação desses locais. Além disso, entrevistas foram aplicadas para entender as representações sociais dos moradores em relação a esses ambientes.

Observações sistemáticas dos córregos e seu entorno foram realizadas, com um olhar direcionado para os seguintes aspectos: a forma como se encontra o córrego - canalização aberta, fechada ou sem canalização; uso do solo - casas, áreas de lazer (praças, equipamentos, campos de futebol, quadras de esporte, etc.); disposição de resíduos no local - lixo doméstico, entulhos, animais mortos, restos de jardinagem e podas de árvores, etc.; presença ou não de vegetação bosqueamento ou mata ciliar; se há manutenção da área pela administração pública e como o espaço é utilizado pela população.

\section{A CIDADE PRESIDENTE PRUDENTE E SUAS ÁGUAS}

A escolha do local para a fundação das Vilas Goulart (1917) e Marcondes (1919), que deram origem a Presidente Prudente, foi diferente de 
muitos povoados que escolhiam como ponto principal a proximidade com os rios. A Estrada de Ferro Sorocabana foi o marco primordial para a criação da cidade, assim como para todos os demais núcleos urbanos que surgiram ao longo dessa linha férrea.

O núcleo urbano inicial visava amparar a comercialização de terras rurais, em um momento em que "a terra já havia se transmudado em mercadoria” (SPOSITO, 1983). A falta de recursos e a necessidade de atrair novos compradores de terras levaram os fundadores da cidade, assim como os próprios moradores a realizassem serviços de melhoramento urbano. Desta forma, o processo de expansão urbana seguiu, na época, a política de loteamento implementada pelos coronéis fundadores das vilas, que permitiu o rápido povoamento da cidade (SPOSITO, 1983).

Porém, a expansão urbana, que no seu planejamento ou na falta dele, não considerou os elementos naturais do local (nascentes, córregos, vegetação), trouxe consequências negativas para os cursos d'água.

No núcleo urbano central as erosões geralmente afetavam as ruas e as margens dos córregos, que já haviam sido impactados pela remoção da mata ciliar, fazendo com que o local perdesse suas características naturais.

Além disso, quando o poder público tentou resolver o "problema" de abastecimento de água da cidade, os córregos se tornaram cada vez mais degradados e foram usados como escoadouro de resíduos. Consequentemente, os fundos de vale não foram incorporados à expansão urbana, tornando-se lugares desabitados, usados para a destinação de resíduos e esgoto a céu aberto (SUDO; LEAL, 1996).

Mesmo após várias administrações, o que predominava era a necessidade de elementos urbanísticos que embelezassem a cidade. Desta forma, é evidente que Presidente Prudente foi projetada para dar suporte às fazendas de café e servir de ponto de chegada dos comerciantes. Apesar da crise cafeeira da década de 1930, Presidente Prudente não parou de crescer graças ao algodão, a nova cultura implementada na região. Ao longo do tempo, novos objetos foram sendo fixados na área urbana e a cidade ganhou novas formas: instituições administrativas, religiosas e de prestação de serviços; o posto de expurgo de sementes de algodão; e serviços constantes de sarjetas e calçamento das ruas. A vegetação deu lugar a essa materialidade que, após a ocupação das áreas de topos próximas à linha férrea, gradualmente passa a se direcionar para as vertentes e para os fundos de vale.

Barros (2009) destaca que Presidente
Prudente, em 1950, ainda não tinha cobertura total de fornecimento de água potável canalizada. Naquela época, os problemas ambientais estavam em ascensão e, segundo Amorim (2000, p. 18), decorriam do "acelerado e desordenado crescimento" da cidade,

[...] fruto tanto do êxodo rural devido às transformações ocorridas no campo, principalmente à substituição de produtos agrícolas pela pecuária a partir de 1960, como pela migração das pessoas das cidades próximas de menor porte, reduzidas nos últimos anos pela perda de população, que se tem dirigido para Presidente Prudente em busca de melhores condições de vida e emprego (AMORIM, 2000, p. 18-19).

Entre as décadas de 1950 e 1970, indústrias relacionadas ao gado (frigoríficos e curtumes), foram instaladas nos fundos de vale, atraindo assim a população rural. Presidente Prudente já era reconhecida como a "Capital Regional da Alta Sorocabana”, quando a cidade estende sua influência para uma área mais ampla, tornandose a sede da $10^{\mathrm{a}}$ região administrativa, abrangendo 50 municípios e oferecendo uma variedade de serviços que, associados ao seu comércio expressivo, acabaram atraindo um grande contingente populacional (AMORIM, 2000).

Desta forma, os cursos d'água da cidade perderam suas características naturais e foram cada vez mais utilizados como condutores de águas pluviais e residuais de variadas procedências (residências e indústrias), e as áreas de fundos de vale foram escolhidas pela administração pública para o descarte do lixo coletado na cidade. Além disso, os cursos d'água foram considerados barreiras físicas à expansão urbana de Presidente Prudente.

A partir do início da década de 1970, começaram a surgir novos loteamentos implantados em descontínuo à malha urbana, sem os serviços urbanos básicos para moradia, como asfalto, esgoto e água encanada (SPOSITO, 1983). Assim, com a "tendência à periferização da população de menor renda" (AMORIM, 2000, p. 58), grandes empreendimentos habitacionais foram implantados, atingindo os fundos de vales. Entres eles, o Conjunto Habitacional Ana Jacinta, o maior localizado em áreas de nascentes dos córregos que deságuam na Represa Santo Anastácio, que é responsável por $30 \%$ do abastecimento da população prudentina. E, assim, ocorreu o processo de expansão urbana de Presidente Prudente que se sobrepôs aos córregos das bacias hidrográficas do Rio do Peixe 
e do Rio Santo Anastácio (Figura 1).

$\mathrm{Na}$ falta de um planejamento adequado, em que os cursos d'água aparecessem como parte integrante da paisagem urbana, os fundos de vale foram, ao longo do tempo, ocupados pelo movimento de estruturação da cidade e as obras de engenharia surgem como resposta imediata aos problemas nessas áreas instalados.

Figura 1 - Mapa da rede hidrográfica e expansão territorial urbana de Presidente Prudente - SP (1919 - 2016).

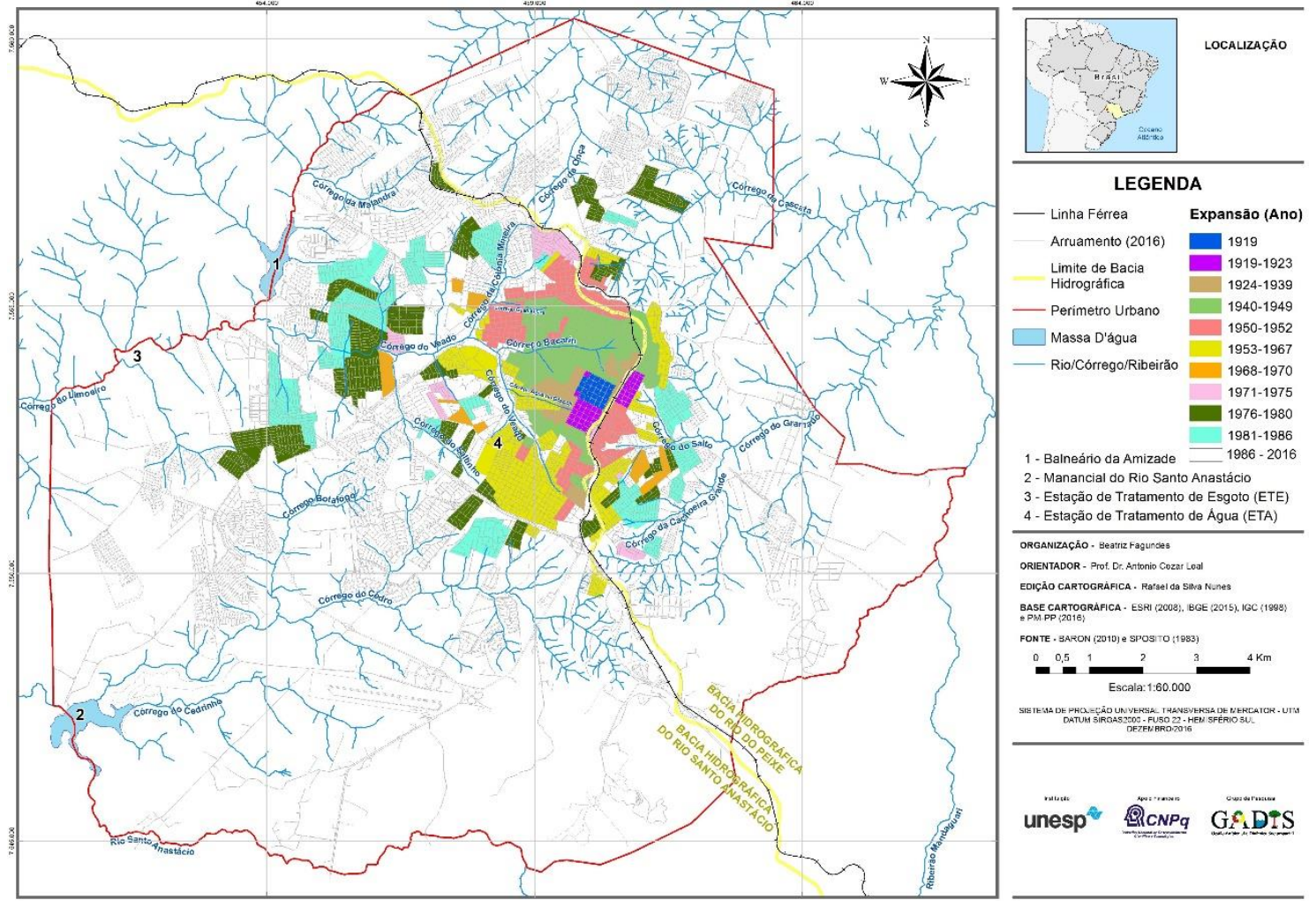

Fonte: Fagundes (2018, p. 144).

\section{OS CURSOS D’ÁGUA E A POLÍTICA DE CANALIZAÇÃO}

No Brasil, existem vários órgãos federais, estaduais e municipais que, habilitados por lei, são responsáveis pela proteção e melhoria da qualidade ambiental em diversas escalas. Entre esses órgãos públicos está o Sistema Nacional do Meio Ambiente (SISNAMA), do qual fazem parte desta estrutura o Conselho Nacional do Meio Ambiente (CONAMA) e o Ministério do Meio Ambiente (MMA). Há diversas leis, decretos e resoluções que formam o arcabouço legal responsável pela proteção do meio ambiente, ao qual a administração pública municipal deve recorrer para planejar, organizar e expandir a cidade de forma a garantir qualidade de vida em equilíbrio com a proteção do meio ambiente -, com especial atenção aos córregos urbanos.

Presidente Prudente adotou um modelo de expansão urbana que favoreceu o setor imobiliário, com obras urbanísticas voltadas aos aspectos sanitários e estéticos para o embelezamento da cidade e expansão do sistema viário (SPOSITO, 1983; MARISCO, 1997). Desde a aprovação do primeiro Código de Obras em 1949, novas leis foram criadas, "entre ordinárias e complementares, ou seja, mais de 6 leis a cada ano tratando de ordenar, organizar e regular seu espaço urbano" em equilíbrio com elementos naturais, mas estes não foram priorizados (MELAZZO; SPOSITO, 2002, p. 129).

Segundo Ikuta (2003) sempre houve um distanciamento entre o que dizem as leis e a realidade de Presidente Prudente, principalmente, em razão de um planejamento que não considerou as leis de proteção a essas águas.

O primeiro Plano Diretor de Presidente Prudente foi criado entre 1968-1969. Nesse momento, ocorria à industrialização e o aumento do processo de urbanização das cidades brasileiras e, assim, o planejamento urbano era fundamental. O Plano Diretor previa estimular e favorecer o desenvolvimento do município, 
através da implantação de um polo de desenvolvimento industrial. Priorizava o modelo compacto da cidade, de forma contínua à malha urbana existente, que se iniciou pelas áreas de topo em direção aos fundos de vale (PLANO..., 1969).

Godoy (1989, p. 1) critica este plano diretor, apontando a falta de importância dada aos "condicionantes de caráter geológico-geotécnico no estabelecimento de diretrizes para a implantação da malha urbana e para as previsões de expansão da cidade”. O autor afirma que a ocupação dos espigões divisores de água e o avanço da malha urbana pelas áreas de nascentes e fundos de vale são características de cidades em que seu núcleo inicial surgiu seguindo o traçado das ferrovias. Argumenta, ainda, que a desatenção dada ao comportamento do meio físico nesse tipo de ocupação tem se refletido em prejuízos econômicos, deterioração do meio ambiente e danos sociais. Assim, essa forma de ocupação levou a canalização de alguns córregos e interferiu danosamente sobre vales e canais pelo entulhamento das cabeceiras em decorrência da erosão.

O Plano Diretor de Presidente Prudente, como um instrumento de planejamento e regulação das atividades urbanas, deveria apoiar a administração da cidade, porém em nenhum momento, nesse período, ele se constituiu em um elemento importante da política de desenvolvimento urbano. Isso fica claro porque, mesmo com o Plano Diretor de Desenvolvimento Integrado pronto, a gestão administrativa em exercício (1969-1973) não implementou o documento (MARISCO, 1997, p. 71).

Foi somente na administração seguinte (1973-1977), que o plano da cidade, mesmo desatualizado, foi implantado (MARISCO, 1997). O Plano Diretor foi aprovado, com o intuito de solicitar recursos do Governo Federal para desenvolver um projeto de "recuperação dos fundos de vale". Os recursos permitiram à canalização fechada dos córregos na área central, integrando áreas consideradas problemáticas, por meio de vias de circulação, aos demais espaços ocupados da cidade.

Com esses recursos federais, a municipalidade em 1976, implantou o projeto "Fundo de Vale" cujo objetivo previa o saneamento ambiental da área onde está localizado o trecho inicial do Córrego do Veado, possibilitando a construção de uma extensa área verde para lazer e esportes chamado "Parque do Povo", "recuperando" assim o fundo de vale que estava em avançado processo de degradação ambiental (Figura 2).

No entanto, o Parque do Povo, um dos principais espaços públicos de lazer da cidade, foi construído desobedecendo ao Código Florestal de 1965 (SAWADA et al., 2007). Posteriormente, em 1978, com mais recursos do Governo Federal novas obras foram realizadas em áreas um pouco mais afastadas do núcleo urbano central. Sempre com o objetivo de "recuperar os fundos de vale" e melhorar o sistema viário, canalizações fechadas foram realizadas com a subsequente construção de espaços públicos de lazer (HORA, 1997).

Desta forma, vários cursos d'água receberam canalização fechada antes e mesmo após 1965 , quando foi aprovada a Lei Federal 4.771/65 (BRASIL, 1965), regulamentando a proteção dos cursos d'água e respectivas áreas de preservação permanente.

O controle das obras de canalização inicia-se somente com a obrigatoriedade das outorgas de canalizações dos córregos. No início dos anos 90 foi aprovada a Lei no 7.663/1991, que instituiu a Política de Recursos Hídricos do Estado de São Paulo, que em 1997 foi reforçada pela Lei Federal 9.433/1997, que vem reforçar, numa escala nacional, o gerenciamento dos recursos hídricos. O DAEE fica responsável em "cadastrar os usuários e outorgar o direito de uso dos recursos hídricos", quanto aos aspectos qualitativos e quantitativos, bem como aplicar as sanções previstas em lei (SÃO PAULO, 1991).

No entanto, mesmo com a obrigatoriedade do pedido de outorga, a prática de canalização fechada continua no espaço urbano de Presidente Prudente. Por essa razão, o Ministério Público Estadual através da Promotoria do Meio Ambiente resolveu intervir, recomendando ao DAEE não mais autorizar canalização do tipo fechada na cidade. $\mathrm{O}$ relatório finalizado $\mathrm{e}$ publicado em novembro de 2005 considerou que para preservar o meio ambiente, a paisagem, o referencial da natureza à população, além de evitar eventuais riscos e danos, a melhor alternativa técnica que contempla o ambiente e o interesse público seria: a construção de canais abertos para os cursos d'água (SÃO PAULO, 2005a). 
Figura 2 - Parque do Povo - Canalização do trecho inicial Córrego do Veado

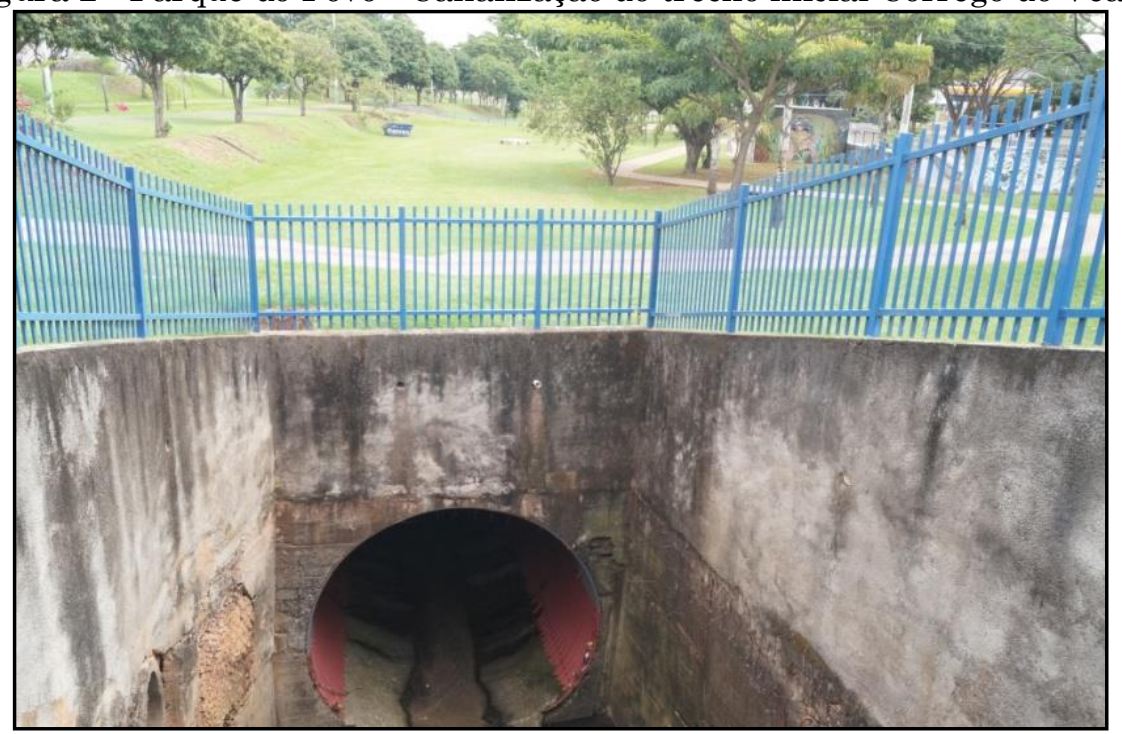

Fonte: Fagundes (2018, p. 170).

Porém, mesmo após essa recomendação, a Prefeitura Municipal de Presidente Prudente persistiu em enviar solicitações de outorga para a canalização fechada dos córregos. Nesse sentido, o DAEE criou uma normativa fundamentada na recomendação do Ministério Público Estadual, determinando que todos os escritórios locais e regionais do DAEE não autorizem mais as canalizações fechadas. A recomendação veio da Promotoria do Meio Ambiente de Presidente Prudente e tornou-se regra geral, proibindo a canalização fechada em todo o estado de São Paulo (SÃO PAULO, 2005b, p. 54).

Assim, ao analisar as outorgas de canalização, fica claro que a prefeitura, através de sua equipe técnica, lida com as águas na área urbana como um "elemento sistêmico" (SAHR, 2015, p. 11), que deve circular nas redes canalizadas de saneamento e de esgoto. Além disso, na elaboração dos requerimentos de outorga, a equipe técnica segue o protocolo exigido pelo DAEE e continua a implementar projetos de urbanização nos fundos de vale, que seguem um modelo padrão, independente da área a ser aplicado - canalização fechada com espaços públicos de lazer construídos sobre os córregos - com requerimentos de solicitação em que apenas o local e o nome do córrego são alterados, mas o texto como um todo permanece o mesmo.

O DAEE também examina, com sua equipe técnica, esses requerimentos, apoiado nas regras de outorga e nas normas vigentes, com a atenção maior voltada ao planejamento e execução da obra para evitar inundações na área urbana.

Desta forma, quando a outorga se apresenta como um mero instrumento burocrático, não cumpre seu principal objetivo, ou seja, "controlar a qualidade e a quantidade dos usos das águas e assegurar o direito de acesso aos recursos hídricos para todos" (SÃO PAULO, 1991). Além disso, isso abre caminho para que a administração pública, através da legalidade, realize as canalizações, repetindo a má prática de atuar nas consequências ao invés de mitigar as causas, prejudicando ainda mais as bacias hidrográficas nas áreas urbanas e, consequentemente, nas áreas rurais. Assim, a administração pública tem o papel de "controlar" as águas dos córregos através das canalizações, muitas vezes consideradas ou divulgadas como alternativas para solucionar um problema existente resultante de um mau planejamento urbano que ignorava as águas no espaço urbano.

Existe, portanto, um círculo vicioso em que a prefeitura faz os pedidos das outorgas de canalização e o DAEE os acata, muitas vezes, sem grandes preocupações em relação aos aspectos ambientais. Desta forma, os projetos de urbanização para as áreas de fundo de vale copiam o modelo antigo usado para o Parque do Povo, que é bem aceito pela maioria da população, como é o caso do espaço público "Parque do Povo da Vila Geni" (Figura 3), construído em uma área antes degradada, sobre o trecho canalizado do Córrego da Colônia Mineira. 
Figura 3 - Parque do Povo da Vila Geni -trecho do Córrego da Colônia Mineira

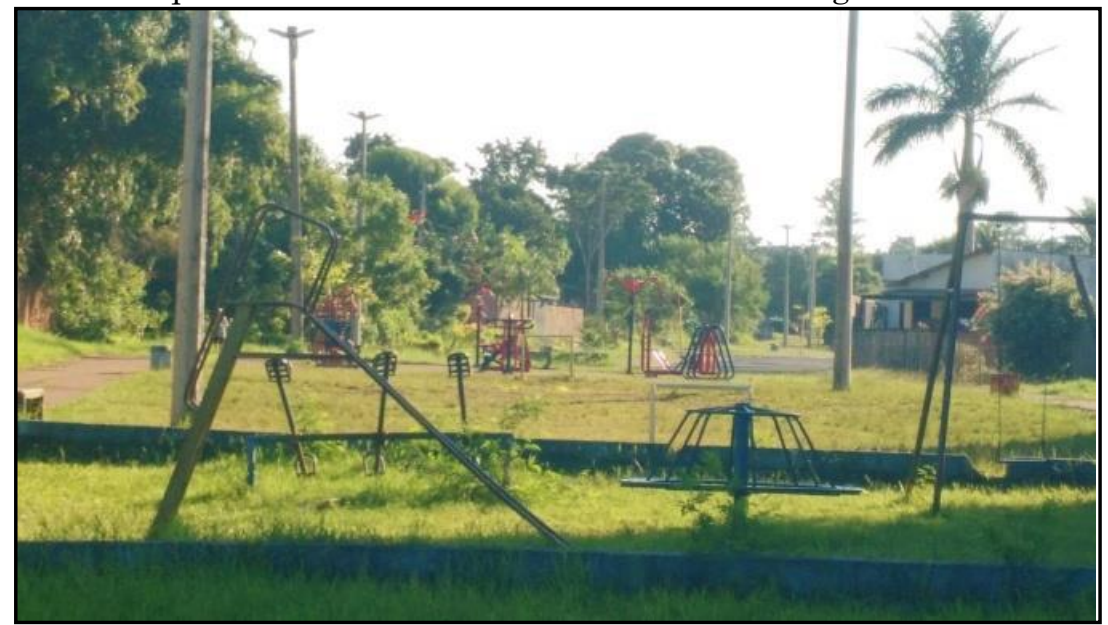

Fonte: Fagundes (2018, p. 230).

Nesse sentido, os projetos de recuperação de áreas de fundos de vale resultaram em várias obras de canalização em diversos bairros da cidade. A concretização dessas obras, ao longo do tempo, aliada as propagandas constantes divulgando a canalização como a solução para os problemas ambientais nos fundos de vale contribuíram para a criação de representações sociais que não valorizam as águas na paisagem urbana. Hora (1997) aponta que essas ações contribuem para o aumento da popularidade dos prefeitos, assim como aconteceu com as obras do Parque do Povo, que serviram de carro-chefe em campanhas políticas para eleger o candidato do mesmo partido do prefeito que iniciou as obras do parque.

Existe uma "cultura de canalização dos córregos", que articula interesses políticos com o processo de urbanização que não considerou os córregos como parte integrante da paisagem. Essa cultura afetou as partes à jusante das bacias hidrográficas e cursos d'água e foi vista pelos olhos da população como problema a ser resolvido.

Nas palavras de Caetano (2011) a canalização faz parte da "tradição política brasileira" que pressupõe que preservar um rio, sem obras concretas, é um tipo de ação que "os governos não gostam de realizar porque elas dão pouca visibilidade".

Silva (2002) destaca como a figura dos políticos que realizaram obras materializadas na paisagem é "concebida na memória popular",

[...] como homens que amavam a cidade e faziam de tudo para o seu "progresso". Essa associação se dá porque eles tiveram cuidado de petrificar as suas obras no espaço, ou seja, cuidar para que elas fossem sobretudo palpáveis. Tais obras são antes de tudo algumas materialidades do "sonho de uma cidade ideal", são desejos que o olhar do citadino quer alcançar concretamente na cidade. Os artefatos materiais existentes no espaço dignificam o nome daqueles que os construíram. A prática de materializá-los, aproveitando-se do contexto histórico favorável, das alianças e de toda uma série de ardis políticos, garantem a lembrança desses "bem feitores" no futuro. Prática, aliás, que adquiriu muitas raízes no Brasil e não foi diferente nesta cidade. Ficaram, as outras pautas da agenda política, materialmente menos visíveis, a cargo da paliativa caridade das instituições filantrópicas ou de outros políticos, talvez (SILVA, 2002, p. 55).

A política urbana local insistia nessa relação predatória com os rios urbanos, sem visualizar alternativas, como se esse fosse o caminho natural, único e intencional a seguir, de "petrificar suas obras no espaço" (SILVA, 2002, p. 55). A ação da Promotoria do Meio Ambiente na proibição de canais fechados mostrou-se de certa forma positiva, mas apenas no sentido de proteger a vegetação dos fundos de vale. Em relação aos cursos d'água, esta medida acaba sendo ineficiente. No entanto, tudo isso demonstra que, quando as autoridades estão dispostas e os órgãos públicos criados para proteger o meio ambiente desempenham seu papel, as leis são efetivamente aplicadas.

Por outro lado, como apontaram as entrevistas, existem "conflitos" levantados pela população contra as ações ambientais da administração pública e Promotoria do Meio Ambiente. Esses "conflitos" só aparecem quando a área atinge um estágio avançado de degradação, decorrente do mau planejamento e de uma expansão urbana sem limites. Além 
disso, novas áreas de loteamento em Presidente Prudente frequentemente desobedecem às leis urbanas e ambientais.

Neste estudo, os ambientes mais degradados foram registrados nas áreas adjacentes a cursos d'água não canalizados, com lixo nas margens e leitos, descarte de entulhos, restos de poda de árvores e jardinagem, móveis e até lixo eletrônico (Figura 4).

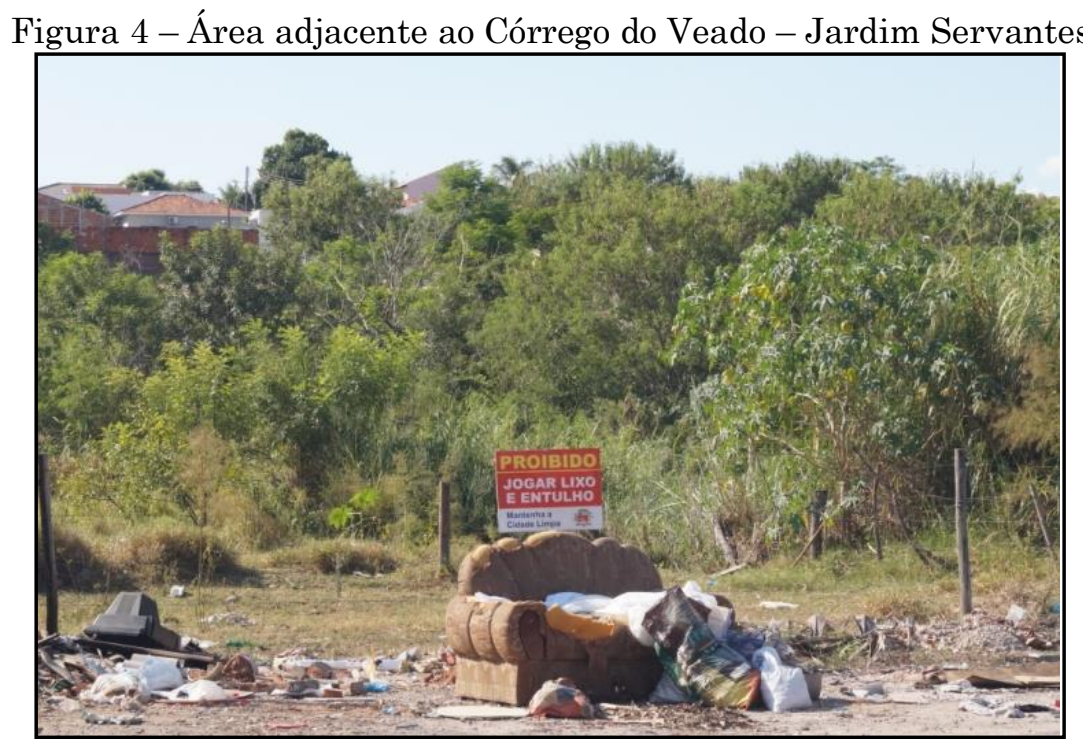

Fonte: Fagundes (2018, p. 254).

Foram encontradas várias irregularidades nos córregos pertencentes às bacias hidrográficas de manancial como: buracos nas cercas de proteção para o descarte de restos de jardinagem, entulho e animais mortos. Uma quantidade considerável de lixo foi encontrada nas áreas adjacentes às Áreas de Proteção Permanentes (APPs).

A figura 5 mostra a rede hidrográfica no tecido urbano de Presidente Prudente. Os cursos d'água foram impactados pela expansão urbana, e as obras de engenharia se tornaram a solução para os problemas resultantes, incluindo as inundações. A bacia hidrográfica do Córrego do Veado foi a mais afetada pelas intervenções realizadas nos cursos d'água, porque a expansão urbana foi mais significativa a oeste da ferrovia.

Figura 5 - Mapa da rede hidrográfica na malha urbana de Presidente Prudente-SP (2018)

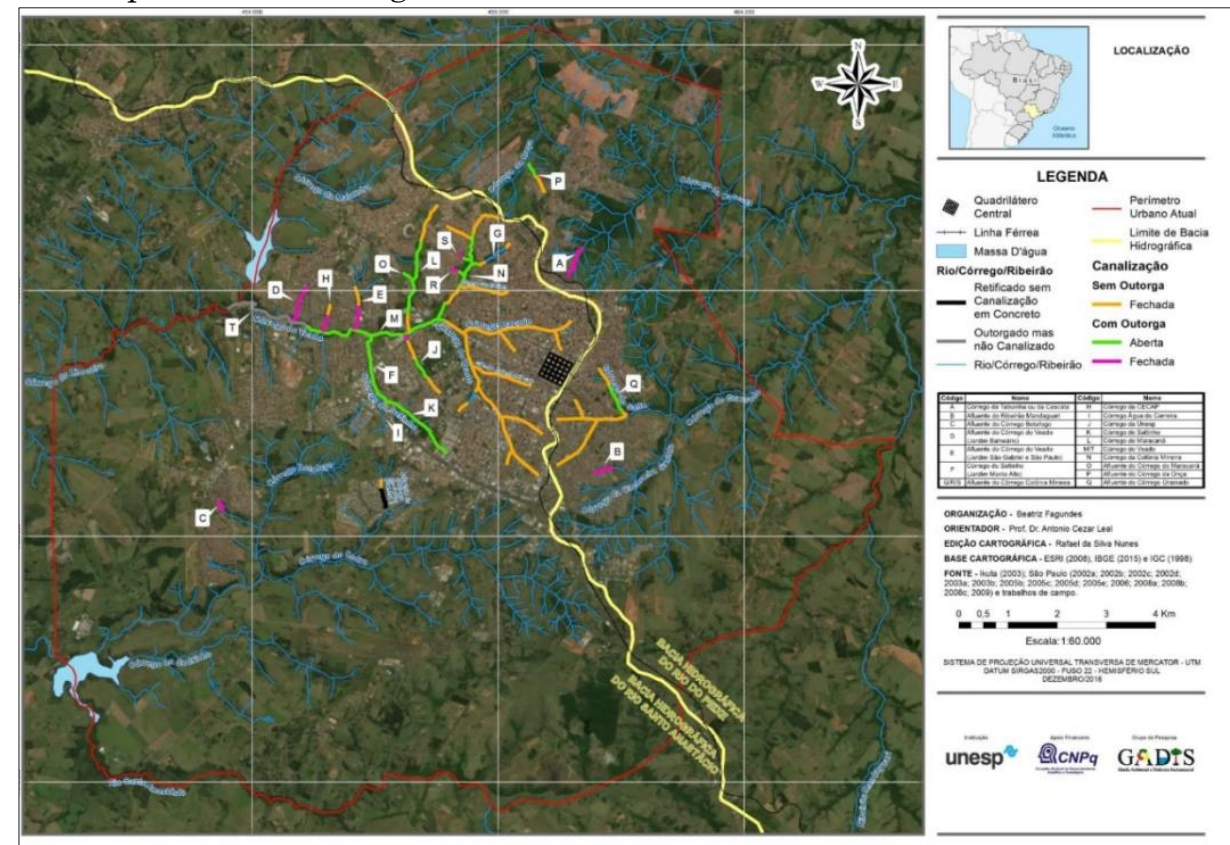

Fonte: Fagundes (2018, p. 186). 
Em uma cidade de tantas águas como Presidente Prudente, é muito raro encontrar ambientes nos quais elas foram valorizadas como elemento paisagístico; como Balneário da Amizade, Cidade da Criança, Praça Municipal Lagoa dos Patos (Figura 6) e alguns condomínios residenciais, como o Damha I, que valorizaram os cursos d'água e nascentes em seu projeto; no entanto, são condomínios privados com acesso restrito.
Portanto, a população raramente vê as águas da cidade em parques lineares que não circulam por galerias de concreto. Esses ambientes, pelos quais circulam as águas de Presidente Prudente, não foram e não têm sido preservados.

Além disso, faltam soluções alternativas, criatividade ou interesse político em apresentar novos caminhos para essas águas, valorizando-as e incluindo-as em projetos ambientais em fundos de vale.

Figura 6 - Parque Municipal Lagoa dos Patos

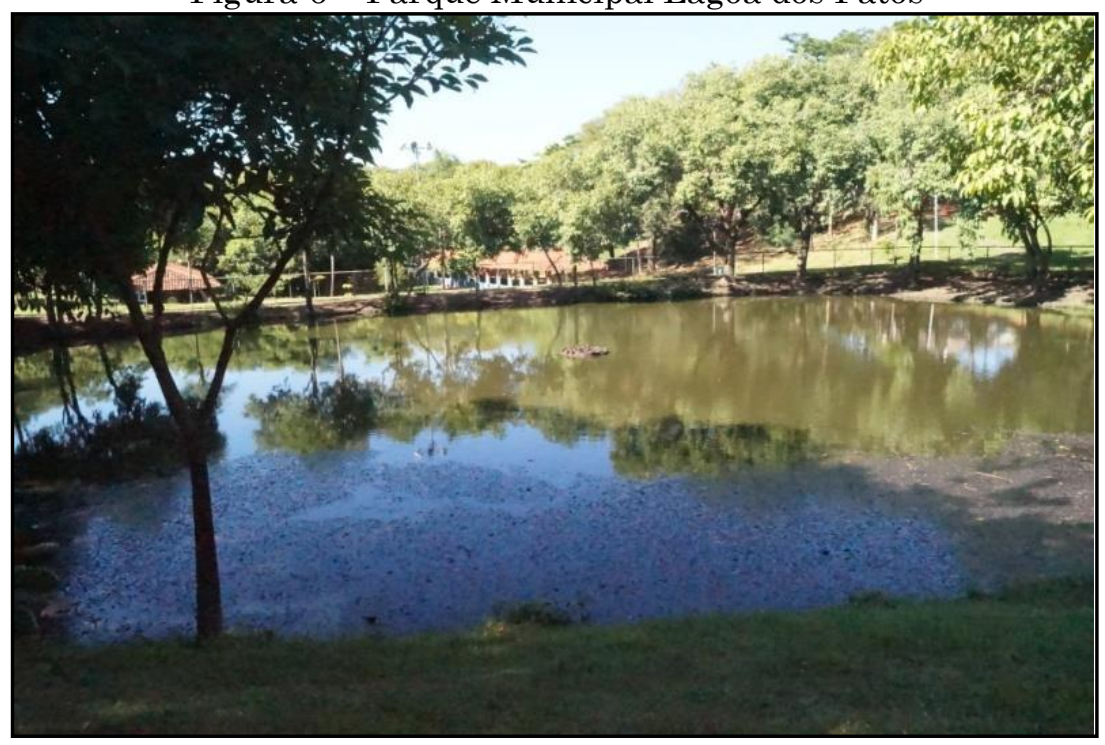

Fonte: Fagundes (2018, p. 211).

\section{CONSIDERAÇÕES FINAIS}

Os pequenos córregos que atravessam o tecido urbano de Presidente Prudente foram vistos pela administração pública como parte de um sistema artificial de canalização fluvial, afastamento de águas pluviais e residuais e como barreira à expansão urbana.

Presidente Prudente seguiu um modelo de planejamento voltado ao setor imobiliário e, muitas vezes, não considerou as águas como elemento integrante da paisagem urbana.

A expansão urbana de Presidente Prudente aconteceu e se sobrepôs aos córregos, sem observância ao marco legal de proteção dos cursos d'água. Tal processo, associado à falta de ambientes urbanos valorizando a presença das águas na paisagem, contribuíram para que a população aceitasse as canalizações como o destino final para as águas urbanas.

\section{REFERÊNCIAS}

AMORIM, F. O. Parque de Uso Múltiplo (PUM) em Presidente Prudente, São Paulo - propostas de intervenção no espaço urbano. In: SIMPÓSIO DE PÓS-GRADUAÇÃO EM ENGENHARIA URBANA, 2., 2009, Maringá. Anais... Maringá: [Departamento de Engenharia Civil/Universidade Estadual de Maringá], 2009. Disponível em: http://www.dec.uem.br/eventos/ii_simpgeu/arqu ivos/Trabalhos/122.pdf. Acesso em: 03 jan. 2018.

AMORIM, M. C. C. T. O clima urbano de Presidente Prudente (SP). 2000. 374 f. Tese (Doutorado em Geografia) - Faculdade de Filosofia, Letras e Ciências Humanas, Universidade de São Paulo, São Paulo, 2000.

BARROS, C. C. Saneamento básico em Presidente Prudente - São Paulo: histórico do abastecimento de água, da coleta e do tratamento de esgoto no município. 2009. $150 \mathrm{f}$. Trabalho de Conclusão de Curso (Bacharelado em Geografia) - Faculdade de Ciências e Tecnologia, Universidade Estadual Paulista, Presidente Prudente, 2009.

BRASIL. Lei $\mathbf{n}^{\circ} \mathbf{4 . 7 7 1}$, de 15 de setembro de 1965. Institui o novo Código Florestal. Brasília, 
DF, 1965. Publicado no DOU de 16 set. 1965 e retificado em 28 set. 1965. Disponível em: http://www.planalto.gov.br/ccivil_03/leis/L4771i mpressao.htm. Acesso em: 7 maio 2017.

CAETANO, J. Os fundos de vale da política brasileira. Portal Prudentino, Presidente Prudente, 10 fev. 2011. [Seção Blogs] - Blog História e Política. Disponível em: http://www.portalprudentino.com.br/blog.php?i $\mathrm{d}=81 \&$ post $=100$. Acesso em: 18 jan. 2018.

FAGUNDES, B. As águas da cidade de Presidente Prudente - SP - Brasil: Memória e Representação Social. 2018. 367 f. Tese (Doutorado em Geografia) - Faculdade de Ciências e Tecnologia, Universidade Estadual Paulista, Presidente Prudente, 2018.

GODOY, M. C. T. F. de. Mapeamento geotécnico preliminar da região urbana de Presidente Prudente - SP. 1989. 2 v. Dissertação (Mestrado em Geotecnia) - Escola de Engenharia de São Carlos, Universidade de São Paulo, São Carlos, 1989.

HORA, M. L. F. O Projeto Cura III em Presidente Prudente: uma porta para a cidade? 1997. 273 f. Dissertação (Mestrado em Geografia) - Faculdade de Ciências e Tecnologia, Universidade Estadual Paulista, Presidente Prudente, 1997.

IKUTA, F. A. A cidade e as águas: a expansão territorial urbana e a ocupação dos fundos de vales em Presidente Prudente-SP. 2003. 191 f. Dissertação (Mestrado em Geografia) Faculdade de Ciências e Tecnologia, Universidade Estadual Paulista, Presidente Prudente, 2003.

MARISCO, L. M. O. Contribuição ao estudo do planejamento municipal no Brasil: o plano diretor de desenvolvimento integrado de Presidente Prudente (SP) - 1969. 1997. 276 f. Dissertação (Mestrado em Geografia) Faculdade de Ciências e Tecnologia, Universidade Estadual Paulista, Presidente Prudente, 1997.

MELAZZO, E. S.; SPOSITO, M. E. B. Plano diretor e legislação urbanística. In: MELAZZO, E. S.; GUIMARÃES, R. B. (Org.). Conjuntura Prudente 2002. Presidente Prudente: GAsPERR/FCT/UNESP, 2002, p. 129-131.

PLANO Diretor de Presidente Prudente. São Paulo: CPEU/FAUUSP, 1969. 5 v. Estudo elaborado para a Prefeitura Municipal de Presidente Prudente, Estado de São Paulo.

SAHR, W.-D. Apresentação. In: FAGUNDES, B. A problemática da água como representação social: um estudo de caso com os moradores do Bairro Alto da XV em Guarapuava-PR. Jundiaí: Paco, 2015, p. 9-12.

SANTOS, M. A natureza do espaço: técnica e tempo, razão e emoção. São Paulo: EDUSP, 2002. p. 13-259.

SÃO PAULO. Lei $\mathbf{n}^{\circ} \mathbf{7 . 6 6 3}$, de 30 de dezembro de 1991. Estabelece normas de orientação à Política Estadual de Recursos Hídricos bem como ao Sistema Integrado de Gerenciamento de Recursos Hídricos. São Paulo, SP, 1991. Publicada na Assessoria Técnico-Legislativa em 30 dez. 1991. Disponível em: http://www.al.sp.gov.br/repositorio/legislacao/le i/1991/lei-7663-30.12.1991.html. Acesso em: 03 out. 2017.

SÃO PAULO. Ministério Público. Assunto: Canalização de córregos na cidade de Presidente Prudente - SP. Parecer técnico. Autos: PT no 439/05. Presidente Prudente, 11 nov. 2005a.

SÃO PAULO. Secretaria de Recursos Hídricos, Saneamento e Obras. Departamento de Águas e Energia Elétrica. [Outorgas - canalização]. São Paulo, 2005b. Requerimento de outorga de direito de uso de recursos hídricos ao Departamento de Águas e Energia Elétrica DAEE. Processo no 9400819, Provisória 12.

SAWADA, F. T.; TRAJANO, G. S.; NUNES, L. F. A.; MALAVAZZI, M. A.; FREITAS, R.; SILVA, E. W. A. Análise espaço-temporal do Parque do Povo de Presidente Prudente a partir de fotos aéreas e imagem orbital. 2007. Trabalho de Conclusão de Curso (Bacharelado em Engenharia Cartográfica) Faculdade de Ciências e Tecnologia, Universidade Estadual Paulista, Presidente Prudente, 2007. 1 CD-ROM.

SILVA, V. C. P. Ícones de uma cidade em expansão: imaginário e memória. 2002. 175 f. Dissertação (Mestrado em Geografia) Faculdade de Ciências e Tecnologia, Universidade Estadual Paulista, Presidente Prudente, 2002.

SPOSITO, M. E. B. O chão em Presidente Prudente: a lógica da expansão territorial urbana. 1983. 230 f. Dissertação (Mestrado em Geografia) - Instituto de Geociências e Ciências Exatas, Universidade Estadual Paulista, Rio Claro, 1983.

SUDO, H.; LEAL, A. C. Aspectos geomorfológicos e impactos ambientais da ocupação dos fundos de vales em Presidente Prudente - SP. Sociedade \& Natureza, Uberlândia. v. 15. 1996. p. 362-367.

SUERTEGARAY, D. M. A. Espaço geográfico uno e múltiplo. In: SUERTEGARAY, D. M. A.; BASSO, L. A.; VERDUM, R. (Org.). Ambiente e lugar no urbano: a grande Porto Alegre. Porto Alegre: Ed. Universidade, 2000. p. 13-34. 